\title{
Status of food safety and food security in India in the perspective of FSSAI
}

\author{
D. Dhara ${ }^{1 *}$, S. Biswas ${ }^{1}$, S. K. Das ${ }^{1}$ and O. Biswas ${ }^{2}$
}

${ }^{1}$ Department of Livestock Products Technology, West Bengal University of Animal and Fishery Sciences, Kolkata - 700 037, West Bengal, India; ${ }^{2}$ Department of Agricultural Engineering, Visva Bharati, Shantiniketan - 731 236, West Bengal, India

\begin{abstract}
Due to rapidly increasing urbanisation and population, India faces many challenges in its hunt for food safety and food security. Quality of food can be compromised at any point of food supply chain from farm to fork by using excessive pesticides, antibiotics, growth hormones or exposure to toxic waste, etc. at the farm level and additives, chemicals, contaminants, environmental pollutants, adulterants, toxic colorants etc. at the processing level. Thus, Food Safety and Standards Authority of India (FSSAI) have been created to govern food regulatory compliance in India as per the Food Safety and Standards Act, 2006. In the last few years of its coming into force, FSSAI has done a lot of ground work for effective implementation of the new food safety regime. Yet, several challenges are required to be counteracted in order to strengthen the regulatory framework for robust enforcement of the FSS Act, 2006.
\end{abstract}

Key words: Food safety, FSS Act 2006, Safe

\section{Highlights}

- Enforcement of food safety regulations.

- Capacity building in States and UTs and its own offices and laboratories.

- Eat Right India.

- Sustainability initiatives.

- Safe, wholesome and hygienic food for all to create 'Swasth Bharat'.

\section{Introduction}

"Food Safety" is an "assurance that food is acceptable for human consumption according to its intended use' as per Section 3.(q) of the Food Safety and Standards Act 2006 (Nijhawan, 2020). Food safety assures that food is safe and wholesome for human consumption and involves handling, preparation, processing or manufacturing and storage of food in ways that prevent food borne illness.

Due to globalisation and rapidly increasing population and urbanisation, India faces many challenges in its quest for food safety (UmaliDeininger and Sur, 2007). Farm level contaminants such as pesticides, hormones, toxic waste, and manufacture level contaminants such as excessive use of additives, chemicals, or adulterations or unhygienic processing, etc. make the food unsafe for consumption (Fung et al., 2018). Thus, quality of food can be compromised at any point of the food supply chain from farm to fork (Kamboj et al., 2020). Therefore, every step poses a challenge for enforcement of food safety regulations.

Previously, food safety of India was under eight different acts and orders that were handled by various ministries and departments related to food (Reddy et al., 2017). However, a single reference point was needed for all matters relating to food safety and standards, regulations and enforcement (Sushila, 2020) and in 2006, it was replaced by the Food Safety and Standards Act (FSSA). The FSSA specifically

*Corresponding Author, E Mail: dhananjoydhara@gmail.com 
replaced eight laws that were in operation before the enforcement of the FSSA (Jairath and Purohit, 2013):

1. The Prevention of Food Adulteration Act, 1954 (37 of 1954)

2. The Fruit Products Order, 1955

3. The Meat Food Products Order, 1973

4. The Vegetable Oil Products (Control) Order, 1947

5. The Edible Oils Packaging (Regulation) Order, 1998

6. The Solvent Extracted Oil, De oiled Meal, and Edible Flour (Control) Order, 1967

7. The Milk and Milk Products Order, 1992

8. Any other order issued under the Essential Commodities Act, 1955 (10 of 1955) relating to food

The Food Safety and Standards Authority of India (FSSAI) is the authority to govern food regulatory compliance in India that has been created as per FSS Act, 2006 and operationalised with the notification of Food Safety and Standards Rules, 2011 along with six regulations with effect from $5^{\text {th }}$ August, 2011.

FSSAI consolidates the laws relating to food under FSSA; regulates the manufacture/process, distribution, storage and import; prescribes standards for food articles, regulates the use of food additives, toxins, antibiotics, pesticides, contaminants, etc.; provides license and registration to food business operators for carrying out business; prescribes packaging and labelling requirements; restricts and prohibits sale of certain products; prohibits misleading advertisements and unfair trade practices for promotion of sale; promotes awareness of the consumers; and ensures availability of safe and wholesome food for human consumption and for matters connected therewith or incidental thereto (Goswami and Mulherkar, 2012).

\section{FSSAI standards}

FSSAI is responsible for framing regulations or specifying standards for all products that are undertaken by 21 Scientific Panels and one Scientific Committee comprising several independent experts and scientists (FSSAI Annual Report 2019-20, 2020-2021). Standards are reviewed by considering the latest developments in food science and nutrition, consumption patterns of consumers, new products and additives, advancement in processing, technology, analytical methods, identification of new risks and feedback from all stakeholders. For effective implementation of FSS Act, 2006, FSSAI notified 21 different regulations through which standards of different foods, controlling of food businesses by giving registration or license, prohibition and restriction on sales of certain products, fixing maximum limits of contaminants, toxins and residues of food products, procedure for laboratory and sampling, food recall, imported products, approval for non-specific food and food ingredients, requirement of organic food, alcoholic beverages, fortification of food, food safety auditing, recognition and notification of laboratories, advertisement and claims, packaging, recovery and distribution of surplus food, safe food and balanced diets for children in school, foods for infant nutrition, labelling and display of packaged products are mentioned (www.fssai.gov.in).

\section{Registration, licensing and compliance}

All food business operators (FBOs) are required to take license or registration under FSSAI (state or central) as per their annual turnover or production capacity or storage capacity to carry out any food business activity in India. By having registration or license under FSSAI, FBO must comply with all the relevant regulations made under FSS Act, 2006. Thus, FSSAI controls all the domestic and imported food products. FSSAI has continuously been taking several efforts for facilitating easy of doing businesses such as implemented cloud based and latest technology and open source environment of Food Safety Compliance System (FoSCoS) for issuing registration and license, informative user interfaces to avoid applicant's common mistakes while filing application for licensing and registration, kind 
of business-wise required mandatory documents, integrated with pan-India online payment gateway, mandatory inspection through FoSCoS/FoSCoRIS App, availability of customised reports for enforcement agencies, availability of third party audit report on FoSCoS, online submission of annual returns, facility for reinstating the application, new version of food consumer grievance system version 2.0, common format of FSSAI license and registration across the country, reduced steps for processing of license, etc. (www.fssai.gov.in).

\section{Imports}

FSSAI has notified its long pending import regulation in 2017. Thus, FSSAI addressed solutions that importers had faced during importing of food items and reduced the information gap between exporter and importer. Now, food imports have been simplified through a single window interface ICEGATE portal where risk based clearance has been implemented.

FSSAI covers 53 entry points including all the major locations of Kolkata, Delhi, Mumbai, Chennai, Tuticorin, and Bengaluru. In various entry points where FSSAI officials cannot be present, the customs officers have been notified as authorised officers to maintain parity of testing and import clearance in 97 locations (www.fssai.gov.in).

\section{Exports}

Till date, export of food products is not coming under the purview of FSSAI. However, several consignments are being rejected at global markets because of food safety issues. Therefore, to reduce such rejections, FSSAI has taken initiative to bring export under its mandate by amending FSS Act, 2006 which is now under draft stage.

\section{Food testing}

FSSAI notifies several private laboratories who are NABL accredited for the purpose of carrying out analysis of foods. Presently, there are 190 notified and 19 referral food testing laboratories (www.fssai.gov.in). Out of 209 laboratories, FSSAI has recognised 12 laboratories as National Reference Laboratory (NRL) and 2 laboratories as Ancillary National Reference Laboratory (ANRL) to set up a country wide standard for routine procedures, validation of testing methods, development of new methods and ensuring proficiency in testing across the food laboratories (www.fssai.gov.in).

FSSAI initiated to strengthen 45 state food laboratories with state-of-the-art facilities. It has made a scheme to give support to state food laboratories for upgrading the infrastructure along with trained manpower for utilizing the sophisticated high quality testing instrument, equipment and machines for a limited period. It has also provided to states mobile units, called "Food Safety on Wheels", for testing of common adulteration of food quickly. Moreover, it has launched Indian Food Laboratories Network (INFoLNeT) which is an online portal where different stakeholders can manage all activities of food testing through the online interface.

\section{Capacity building in states and UTs and its own offices and laboratories}

36 Food Safety Commissioners in different states and UTs and a total of 703 Adjudicating Officers, 667 Designated Officers and 2583 Food Safety Officers involve for enforcement of food safety (FSSAI Annual Report 2019-20, 2020-2021). FSSAI supports states by signing MOU with states. It provides training and capacity building for regulatory and laboratory staff. FSSAI has also strengthened its own staff by recruiting various posts including Central Food Safety Officers (CFSOs). Now, Central Licensing Authority (CLA), previously dependent on State Authority, can proceed for appropriate legal action if any FBO does not comply with the FSS Act, 2006 and rule and regulations made thereunder.

\section{Eat Right India}

The key objective of the Eat Right India movement is to ensure that every Indian has to 
get safe, healthy and sustainable food. It encompasses several initiatives and programs. Demand and supply of safe and healthy foods in a sustainable way is the main aim of these initiatives. The supply-side initiatives are aimed to train and develop capacity buildings of food businesses to promote self-compliance, while the demand-side initiatives are aimed to motivate consumers to demand safe and healthy food. The efforts for the production and consumption of food in a sustainable way are aimed to promote environment-friendly food practices and habits.

\section{Supply-side initiatives}

FSSAI has started a certification program named as Food Safety Training and Certification (FoSTaC) to ensure the presence of a trained and certified Food Safety Supervisor (FSS) on each food business premises. Eat Right Station, Clean Street Food Hub, BHOG (Blissful Hygienic Offering to God) for Places of Worship and Clean and Fresh Fruit and Vegetable Markets, which are picked out to clusters of vendors. The Hygiene Rating scheme has been started for food service establishments such as hotels, restaurants and cafeterias, bakery shops, sweet shops and meat shops.

\section{Demand-side initiatives}

FSSAI strives to change society and its behaviour on a large scale, to attract and educate consumers on eating right. They work on three main areas: Building Consumer Awareness, Addressing Adulteration and Enabling Healthy Choices.

For building consumer awareness, Eat Right Campus and Eat Right School that target individuals in workplaces, institutes, universities, colleges, hospitals, tea estates and jails as well as school children in schools have been esposed. The Eat Right Toolkit has been set up to reach communities at the grass-roots level by training frontline health workers for spreading messages on eating right.

For addressing adulteration, FSSAI developed DART Book for testing food adulterants at home. For testing adulteration in the laboratory of a school, Food Safety Magic Box has been developed. Food Safety on Wheels, called as mobile food testing van, has been distributed across the states to reach remote areas and every corner of the country.

For enabling healthy choice, FSSAI has started mass awareness campaigns among the consumers to reduce salt, fat and sugar in their diets and Trans-Fat Free India@75 to eliminate trans fats by 2022. FSSAI has encouraged manufacturers and other stakeholders for fortifying foods on a large scale for combating micronutrient deficiencies across the country.

\section{Sustainability initiatives}

FSSAI has taken several sustainable initiatives such as Save Food, Share Food for reducing food waste and promoting donation of food, Jaivik Bharat for promoting organic food, Repurpose Used Cooking Oil (RUCO) for making biodiesel, soap or other related products by using repurpose used cooking oil and Sustainable Packaging in Food and Beverage Sector for reducing the use of plastics.

Eat Right India aims to gear up all these initiatives at the national level to ensure that every Indian eats safe, wholesome and healthy food in a sustainable way.

\section{Food securities}

The increased demand for food due to exponential rise in population was met by a combination of scientific and technological advances, government policy, institutional intervention and business investment, innovation and delivery (Cole et al., 2018). Since the onset of the Green Revolution in the year 1967-68, India has avoided famine even in the worst conditions (Somvanshi et al., 2020). Though there are several organisations to combat food security in India, FSSAI plays a major role by controlling food grains and other food products during import. Besides, FSSAI has taken the Indian Food Sharing Alliance (IFSA) initiative to solve the food waste 
and hunger crisis by integrating various partner organizations, Food Recovery Agencies and NGOs. Besides, programs like Integrated Child Development Services (ICDS), Food-for-Work (FFW), Mid-Day Meals, Antyodaya Anna Yojana (AAY), Public Distribution System (PDS), etc. are encouraged to fortify food products with micronutrients to combat malnutrition of the people.

\section{Consumer connects}

Consumers have the right to get information, the right to get choice about safe and nutritious food, the right to be protected from unfair trade practices and the right to get redressal of grievances. FSSAI is devoted to protecting consumer's rights. FSSAI has launched a dedicated 'Food Smart Consumer' portal so that consumers can easily access to facilitate their choices, protect them from unfair practices and ensure prompt redressal of grievances. Under this initiative, consumers can reach the FSSAI through multiple channels such as mobile app, WhatsApp, toll-free number, helpline number, website, etc. Consumers can also lodge their complaint regarding food related issues with the State Authorities through these channels. Besides, FSSAI has launched 'Food Safety Connect' mobile app to connect with consumers and FBOs.

\section{Challenges ahead}

Despite having a legal framework in place, FSSAI is still struggling for proper implementation of FSS Act, 2006 and rules and regulations made thereunder. Firstly, there are insufficient regulatory staffs in states as well as central. Several states and central are in process of recruitment of regulatory staffs. Moreover, additional charges have been given to the Designated Officer and Commissioner of Food Safety of the state. Food Safety Officers, who are the pillars of the implementation of the FSSA, are very less than the actual requirements. Secondly, the insufficient number of laboratories present in the country. The number of laboratories per million people in the country is far lower than other countries like the United Kingdom, Germany, United States, etc. Thirdly, there is also an urgent need to upgrade the infrastructure of food testing laboratories. Fourthly, there are a large number of unorganised sectors which often do not have access to the internet or media messages. So, they, including small and medium enterprises (SMEs), are not adequately aware of FSSAI's rules and regulations. For instance, Reddy et al. (2020) studied the food safety standards followed by street-food vendors in Hyderabad and Delhi in 2017 after the introduction of the Food Safety and Standards Act, 2006 and Rules and Regulations made there under and they found only about one-third of the street-food vendors had registered themselves under FSS Act, 2006 to run food-vending shops, and most street-food vendors were not following basic food safety principles like wearing apron, accessing to tap water, using soap for cleaning utensils, and many did not have refrigerators to store food. Fifthly, FSSA was set up to bring all food products under an umbrella, but, still some products are required to have Bureau of Indian Standards (BIS) license such as infant milk food, infant formula and milk cereal based weaning food, processed cereal based weaning food and follow up formula, packaged drinking water, mineral water, etc. and AGMARK certification such as multi source edible vegetable oil, fat spread, etc. besides FSSAI. The government needs to review the BIS and AGMARK standards separately and merge the BIS and AGMARK standards with FSS Standards so that the food business operators (FBOs) do not face difficulty in following all the mandatory regulations and customers do not face any difficulty to discern the differences in food labelling (Yang, 2019). Sixthly, food business operators including manufacturer, processor, retailer, wholesaler, distributor etc., consumers, and even officials lack awareness of food safety and also lack understanding of the regulation that are constantly updated (Yang, 2019). Lack of information and lack of clarity of regulations are the biggest challenges 
facing food industries. Seventhly, exorbitant costs need to be borne by food business operators for compliance of the FSSA. They need to audit their business from third party and test their products from NABL accredited laboratory which are cost effective.

\section{Conclusions}

The Prevention of Food Adulteration Act, 1955 (PFA) was enacted with the objective of punishing those who tried to profit by selling adulterated foods. But, in the reign of FSSAI, the objective has changed from 'policing' the food industry to ensuring the 'safety' of foods. FSSAI must ensure that all regulations are implemented at all levels through training, inspection and enforcement. Besides, they need to check the costs of food business operators (FBOs) for compliance of the FSSA. They are formulating regulations without proper setup of Government infrastructure. They should set up NABL accredited government laboratory in each state where the cost of testing fees would be minimal. Besides, instead of making mandatory third party audits, regulatory staffs need to be increased for monitoring and inspection.

Initiatives such as Indian Food Sharing Alliance (IFSA), Repurpose Used Cooking Oil (RUCO) and cold chain facilities need to be promoted and streamlined to implement a unified goal of self sufficiency and food security across the nation as lack of the same have been attributed to food spoilage and wastage. Recent approaches are often aimed at specific segments of the value chain network. But, integrated approaches towards continuous monitoring of productivity and yield across

\section{REFERENCES}

Cole MB, Augustin MA, Robertson MJ and Manners JM, 2018. The science of food security. NPJ Sci Food, 2: 14, doi: 10.1038/s41538-018-0021-9

FSSAI Annual Report 2019-20, 2020-2021. New Delhi. Available online at https://fssai.gov.in/upload/ uploadfiles/files/FSSAI_Annual_Report_2019 _20_English_Hindi.pdf [12 Sept., 2021]

Fung F, Wang HS and Menon S, 2018. Food safety in agriculture and animal products, streamlining the availability of products for domestic, import and exports and reducing barriers amongst various segments can help India to achieve its goal of self sufficiency while ensuring food safety and security for all.

As a regulator, FSSAI has done commendable work to develop the food safety ecosystem in India by regulating import and domestic market as well as consumer awareness. But, FSSAI's efforts to provide safe and wholesome food to each citizen depend on the stakeholders and consumers at grassroots levels. As there are huge numbers of stakeholders involved in food business activities in India and huge numbers of consumers are not aware of food safety, its execution is not streamlined yet. It will take time before tangible results are obtained. The use of additives, antibiotics, pesticides and other chemicals in food needs to be re-addressed and regulated as they directly impact the health of the nation. Even, the Hon'ble Prime Minister Narendra Modi has stated during $10^{\text {th }}$ anniversary of the Food Safety and Standards Act 2006 that the cornerstone of the efforts of FSSAI must be to ensure safe, wholesome and hygienic food for all to create "Swasth Bharat" (www.fssai.gov.in).

Conflict of interest: Authors have no conflict of interest in this study.

Author's contribution: DD: Made a preliminary draft of the manuscript; SB: Made conceptualization of this work and critically redrafted; SKD and OB: Added further information and critically redrafted the manuscript.

the 21st century. Biomed J, 41(2): 88-95, doi: 10.1016/j.bj.2018.03.003

Goswami L and Mulherkar C, 2012. India: Indian food safety laws - implications for foreign operators importing food into India. Eur Food Feed. Law Rev, 7(3): 154-156, Available at http://www.jstor.org/ stable/24325374 [12 Sept., 2021] https:// fssai.gov.in [12 Sept., 2021] 
Jairath MS and Purohit P, 2013. Food safety regulatory compliance in India: A challenge to enhance agribusinesses. Indian J Agric Econ, 68(3): 431-48, doi: 10.22004/ag.econ.206346.

Kamboj S, Gupta N, Bandral JD, Gandotra G and Anjum N, 2020. Food safety and hygiene: A review. Int J Chem Stud, 8(2): 358-68, doi: 10.22271/ chemi.2020.v8.i2f.8794

Nijhawan R, 2020. Illbo's Food Safety \& Standards Act, 2006, Rules 2011, Regulations. $21^{\text {st }}$ edn. 1 Vols. pp 6

Reddy AA, Cadman T, Jain A and Vajrala AS, 2017. Food Safety and Standards in India. doi: 10.13140/ RG.2.2.27987.68649

Reddy AA, Ricart S and Cadman T, 2020. Driving factors of food safety standards in India: learning from streetfood vendors' behaviour and attitude. Food Secur, 12: 1201-1217, doi: 10.1007/s12571-020-01048-5
Somvanshi PS, Pandiaraj T and Singh RP, 2020. An unexplored story of successful green revolution of India and steps towards ever green revolution. J Pharmacogn Phytochem, 9(1): 1270-1273, Available at https://www.phytojournal.com/ archives/2020/vol9issue 1/PartU/9-1-256-412.pdf [12 Sept., 2021]

Sushila, 2020. Legal Framework Regulating Food Safety: A Critical Appraisal. Int J Consum Law Pract, 8: 78-93

Umali-Deininger D and Sur M, 2007. Food safety in a globalizing world: opportunities and challenges for India. Agric Econ, 37(S1):135-47, doi: 10.1111/j.1574-0862.2007.00240.x

Yang H, 2019. Food safety in India: status and challenges. Gates Open Res, 3: 1043, doi: 10.21955/GATESOPENRES.1115911.1

Received - 26.09.21, Accepted - 13.11.2021, Published - 01.12.2021

Section Editors: Dr. A. Das, Member, Editorial Board 